\title{
Oxidative stress and microcirculatory flow abnormalities in the ventricles during atrial fibrillation
}

\author{
Andreas Goette ${ }^{1}$, Alicja Bukowska ${ }^{2}$, Christopher H. Lillig ${ }^{3}$ and Uwe Lendeckel ${ }^{3}$ \\ 1 Department of Cardiology and Intensive Care Medicine, St. Vincenz-Hospital Paderborn, Paderborn, Germany \\ ${ }^{2}$ Working Group: Molecular Electrophysiology, University Hospital Magdeburg, Magdeburg, Germany \\ ${ }^{3}$ Institute of Medical Biochemistry and Molecular Biology, Ernst-Moritz-Arndt University, Greifswald, Germany
}

\section{Edited by:}

David R. Van Wagoner, Cleveland

Clinic Lerner College of Medicine of Case Western Reserve University,

USA

\section{Reviewed by:}

Barbara Casadei, University of

Oxford, UK

David R. Van Wagoner, Cleveland

Clinic Lerner College of Medicine of

Case Western Reserve University,

USA

George John Rozanski, University of

Nebraska Medical Center, USA

\section{${ }^{*}$ Correspondence:}

Andreas Goette, Department of

Cardiology and Intensive Care

Medicine, St. Vincenz-Hospital

Paderborn, Am Busdorf 2, 33098

Paderborn, Germany.

e-mail: andreas.goette@med.ovgu.de
Patients with atrial fibrillation (AF) often present with typical angina pectoris and mildly elevated levels of cardiac troponin (non-ST-segment elevation myocardial infarction) during an acute episode of AF. However, in a large proportion of these patients, significant coronary artery disease is excluded by coronary angiography, which suggests that AF itself influences myocardial blood flow. The present review summarizes the effect of AF on the occurrence of ventricular oxidative stress, redox-sensitive signaling pathways and gene expression, and microcirculatory flow abnormalities in the left ventricle.

Keywords: angiotensin, atrial fibrillation, microvascular flow, oxidative stress

\section{INTRODUCTION}

Angina pectoris is a typical symptom in patients with paroxysmal atrial fibrillation (AF). In most of these patients, angina pectoris is associated with mildly elevated cardiac troponin (cTn) levels suggesting a non-ST-segment elevation myocardial infarction (NSTEMI). However, in a large proportion of these patients, significant coronary artery disease can be excluded by coronary angiography despite clinical symptoms (Fuster et al., 2006; Brown et al., 2007). Although the elevated ventricular rate during AF may contribute to the symptoms of angina pectoris (Fuster et al., 2006), angina pectoris develops also in patients with a slow ventricular rate and most patients tolerate fast ventricular rates in sinus rhythm without any clinical symptoms (Van Gelder et al., 2002; Wyse et al., 2002). Recent reports suggest that myocardial blood flow is reduced, whereas coronary vascular resistance is elevated in patients with AF (Kochiadakis et al., 2002; Range et al., 2007). One potential link between AF, abnormal ventricular perfusion, and cardiomyocyte dysfunction is the occurrence of oxidative stress and the disruption of redox signaling through activation of the nicotinamide adenine dinucleotide phosphate oxidase (NADPH oxidase; Kern et al., 2006; Camici and Crea, 2007; Doughan et al., 2008). Repetitive episodes of AF-induced ventricular ischemia may contribute to the development of a pathological vicious cycle combining AF and left ventricular (LV) dysfunction.

\section{VENTRICULAR OXIDATIVE STRESS AND SIGNAL TRANSDUCTION DURING AF}

Reactive oxygen species (ROS) are generated under physiological conditions in the cardiovascular system and act as second messengers in numerous redox-sensitive signal transduction pathways (Figure 1). However, under pathophysiological conditions, chronically elevated amounts of ROS may exert oxidative stress. Historically, the term "oxidative stress" was defined as an imbalance between the generation of ROS and the capacity of the defense systems (Cadenas et al., 1982). During the past decade, this model has evolved based on some key findings: the production of different oxidants affects distinct presets of target proteins through modifications that are specific both with respect to the oxidant and the site of modification, most frequently well-defined cysteinyl side chains. The so-called antioxidant redox systems in the different cellular compartments, e.g., glutathione, NADPH, thioredoxin (Trx), and peroxidases such as the peroxiredoxins (Prx), are, however, not in equilibrium and independently maintained at distinct redox potentials. Oxidative stress may thus, more timely, be defined as the chronic disturbance of redox circuits and redoxresponsive signal transduction pathways (Ghezzi et al., 2005; Jones, 2006, 2008).

Oxidative stress has been implicated as playing a critical role in the pathophysiology of heart and cardiovascular diseases such as heart failure, LV hypertrophy, coronary heartdisease, 


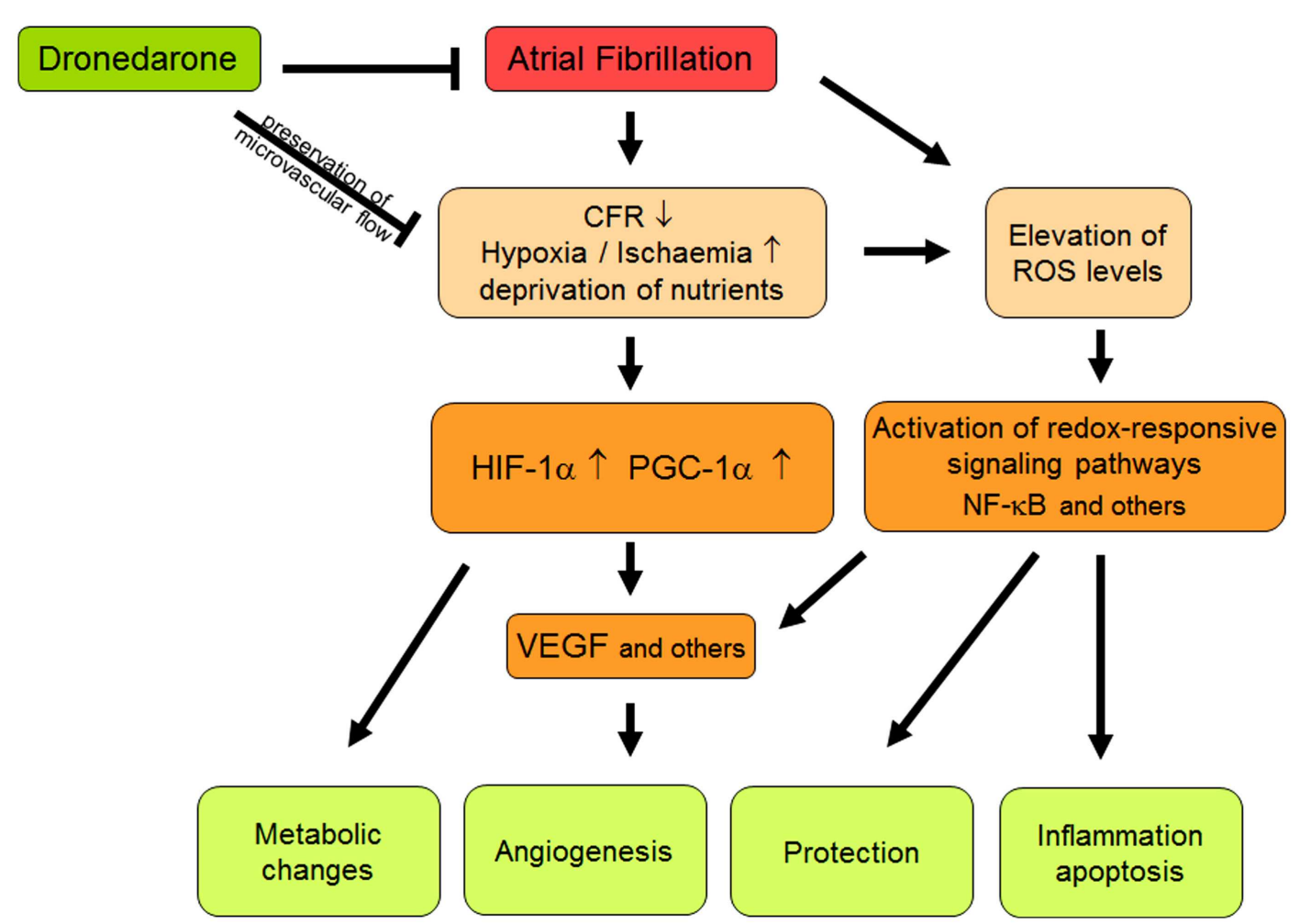

FIGURE 1 | Schematic summary of different interactions between atrial fibrillation, oxidative stress, and flow abnormalities. Abbreviations should be included here are explained in the text.

cardiac arrhythmia. It appears that the oxidative events initiate the disease-dependent tissue remodeling and promote its propagation. Oxidative stress is associated with microvascular flow abnormalities and occurs immediately after new-onset AF likely representing key initiator mechanisms of AF-related ventricular remodeling. This has been shown in patients with lone recurrent $\mathrm{AF}$ and for rapid atrial pacing models (Kochiadakis et al., 2002; Bukowska et al., 2008, 2012; Goette et al., 2009). Irregular RR intervals are considered to be responsible for compromised coronary blood flow reserve, thus preventing the adequate attainment of the increased oxygen demand due to tachycardia (Kochiadakis et al., 2002). In addition, increased catecholamine levels via $\alpha$-adrenergic vasoconstriction may further contribute to AF-induced ischemia (Heusch et al., 2000; Heusch, 2008). AFdependent cardiac remodeling, especially fibrosis, may well contribute to long-term restriction of microcirculation (De Boer et al., 2003). Resulting imbalances of myocardial oxygen supply and myocardial oxygen demand lead to the specific activation of redoxsensitive signaling pathways, that are either protective or part of the pathophysiological process causing onset and progression of AF.

Ischemia facilitates the onset of AF by altering cellular ionic homeostasis, in particular via tachycardia-induced intracellular calcium and sodium overload. Increased spontaneous ectopy is due to increased NCX currents and spontaneous $\mathrm{Ca}^{2+}$-release events (Nishida et al., 2011). In pulmonary veins (PV), hypoxiainduced EAD, and delayed after-depolarizations (DAD) as well as reoxygenation-induced PV burst firing represent important proarrhythmogenic mechanisms (Lin et al., 2012).

Coronary flow can be estimated in vivo using wire-based systems (Goette et al., 2009; Bukowska et al., 2012). Coronary flow reserve (CFR) measurements can be measured using a pressure temperature sensor-tipped guidewires, which allow the simultaneous determination of the fractional flow reserve (FFR). CFR measurements are influenced by flow abnormalities in the epicardial arteries and the microcirculation. In contrast, reduced FFR is specific to epicardial lesions. Recent studies can clearly show that acute episodes of AF induce oxidative stress in the LV myocardium and compromise microvascular blood flow (Goette et al., 2009; Bukowska et al., 2012).

Although it is well established that ischemia creates a substrate for AF maintenance (Sinno et al., 2003; Rivard et al., 2007), the effects of AF on ventricular microcirculation and underlying pathways are less well understood. Impaired intracellular $\mathrm{Ca}^{2+}$ handling as described above together with elevated cardiac and systemic angiotensin II levels are two important factors which very likely contribute to the AF-dependent activation of redox-sensitive signaling pathways in the ventricles. These will be discussed in more detail below.

\section{VASOCONSTRICTORY PEPTIDES REGULATING CORONARY FLOW Angiotensin II}

Vasoactive peptides such as angiotensin II (AngII) and endothelin (ET) play important roles in the regulation of cardiovascular 
function as well as in the pathogenesis of heart and cardiovascular diseases. AF has been associated with increased plasma and tissue levels of angiotensin II (AngII) (Cardin et al., 2003; Goette et al., 2008), which are resulting from increased expression/activity of ACE (Goette et al., 2000).

Angiotensin II mediates its major hemodynamic and pathophysiological effects via the AT1 receptor. Six hours of rapid atrial pacing is sufficient to elevate plasma AngII levels suggesting the very early involvement of this vasoactive molecule in the pathogenesis of AF (Goette et al., 2008). The activation of the AT1 receptor induces a cascade of phosphorylation events that eventually activates MAP kinases, which stimulate the proliferation of fibroblasts, cellular hypertrophy, and apoptosis. Furthermore, activation via the AT1 receptor releases calcium from intracellular stores and activates protein kinase C (PKC). PKC regulates the function of calcium and potassium channels, and phosphorylates $\mathrm{p} 47^{\text {phox }}$ regulatory subunit. The phosphorylation of $\mathrm{p} 47^{\mathrm{phox}}$ plays a pivotal role in the activation of NOX2/NOX1 by providing physical binding domains to another regulatory subunit $\mathrm{p} 67^{\mathrm{phox}}$ (Fontayne et al., 2002). It is noteworthy that both the MAP kinase as well as the calcium/PKC signaling pathways respond to ROS themselves and are regulated by redox effector molecules from the Trx family of proteins (Berndt et al., 2007; Matsuzawa and Ichijo, 2008).

At the atrial level, it is well established that AngII upon binding to its preferred receptor, AT1R, leads to the activation of NADPH oxidase (Oudot et al., 2003; Doughan et al., 2008; Goette et al., 2009). In blood vessels, AngII infusion resulted in increased expression and activity of NADPH oxidase, which was dependent on PKC to some extent (Mollnau et al., 2002). In the murine heart, AngII increased superoxide generation and cardiac hypertrophy involving NOX2 (Bendall et al., 2002). Increased NADPH oxidase activity contributes to elevated ROS production, protein modification, and redox-related gene expression patterns observed in AF (Carnes et al., 2001). Moreover, it has been identified as an independent risk factor for post-operative AF (Kim et al., 2008). Pre-operative treatment with ascorbate prevented AF to a significant extent (Carnes et al., 2001). Similarly, ascorbate reduced the recurrence of AF after cardioversion (Korantzopoulos et al., 2005).

Less is known about the effects of AF on ventricular function and underlying changes in redox-signaling pathway activity and related gene expression. AF is associated with increased coronary resistance, compromised vasodilation (Takahashi et al., 2002), reduced coronary flow (Range et al., 2007), or flow reserve (Goette et al., 2009; Bukowska et al., 2012). As these changes can be largely attenuated by the administration of sartans (Goette et al., 2009). AngII seems to be a major factor linking AF with LV malperfusion and dysfunction. In support of this view, the RAP-induced Ang-IIdependent activation of NADPH oxidase and down-stream effectors of redox-activated signaling cascades, e.g., LOX-1 expression and $\mathrm{F}_{2}$-isoprostane formation, were all attenuated by irbesartan (Goette et al., 2009).

At the molecular level, ANG-II-receptor blockers (ARBs) have been shown to increase $\mathrm{NO}$ availability and it is possible that this effect is mediated by a stronger ANG-II-dependent activation of $\mathrm{AT}_{2}$-receptors. ARBs also attenuate aortic intimal proliferation and markedly decrease the enhanced LOX-1 expression in the aorta of hypercholesterolemic animals (Chen et al., 2000). In a recent study it was shown that application of irbesartan prevents ventricular oxidative stress and microvascular flow abnormalities during $7 \mathrm{~h}$ of AF (Goette et al., 2009). Nevertheless, clinical trials like the ACTIVE study failed to demonstrate a measurable benefit of longterm ARB therapy in patients with AF (ACTIVE I Investigators et al., 2011).

\section{Endothelin-1}

Endothelin-1 (ET-1) exerts its proarrhythmogenic effects by two different ways. First, due to its strong vasoconstrictory activity, ET-1 may induce ischemia which facilitates arrhythmia. Second, upon binding to endothelin receptor A (ET-A), ET-1 affects intracellular calcium handling and, in particular, provokes intracellular $\mathrm{Ca}^{2+}$-waves via IP3-dependent $\mathrm{Ca}^{2+}$-release leading to DAD ( $\mathrm{Li}$ et al., 2005). Furthermore, ET-1 activates PKC and MAP kinases (Sugden, 2003). Atrial stretch is a potent factor promoting the production and release of ET-1 (Bruneau et al., 1997). ET-1 activates NADPH oxidase via the ET receptor-proline-rich tyrosine kinase-2 (Pyk2)-rac1 pathway (Dammanahalli and Sun, 2008). The GTPase, racl, binds to $\mathrm{p} 67^{\text {phox }}$ and activates NADPH oxidase in its GTP-bound state (Rinckel et al., 1999).

Heart failure (Galatius-Jensen et al., 1996; Zolk et al., 1999; Love et al., 2000; Mayyas et al., 2010), valvular disease (Kinoshita et al., 1993), primary pulmonal hypertension (Rubens et al., 2001), but also AF are all associated with increased plasma and cardiac tissue levels of ET-1. Atrial ET-1 levels were correlated with atrial rhythm, atrial size, and hypertension and were associated with hypertrophy, fibrosis, and atrial dilatation (Mayyas et al., 2010). Changes in cardiac and circulating levels of ET-1 have been described in experimental models of myocardial ischemia and in patients with acute myocardial infarction (Hasdai et al., 1994; Brunner et al., 1997; White et al., 2001). Accordingly, a dual ET receptor antagonist has been demonstrated to prevent coronary vasoconstriction during reperfusion of ischemic heart (Besse et al., 2001). AFdependent negative changes in the microcirculation (Goette et al., 2009; Bukowska et al., 2012) contribute to and further enhance increased gene expression and release of ET-1 which, in turn, aggravates coronary vasoconstriction (Neubauer et al., 1991; Hiller et al., 1997) and leads to oxidative stress (Nagase et al., 1990). Although the AngII/ET-1-induced increase of ROS generation is mostly associated with hemodynamic response and development of hypertension, solid evidence shows that these vasoactive peptides via activation of NADPH oxidase mediate changes in vascular architecture and heart damage (Amiri et al., 2004; Zhang et al., 2005).

\section{NADPH oxidase}

It has been suggested that the NADPH oxidase is an important source of ROS in the left ventricle during atrial tachyarrhythmia (Goette et al., 2009; Bukowska et al., 2012). NADPH oxidase was originally discovered in neutrophils, where, during phagocytosis, millimolar quantities of superoxide can be released into the extracellular (phagosomal) compartment. In non-phagocytic cells such as cardiomyocytes, fibroblasts, and endothelial cells, the amounts of produced superoxide are much lower and occur mostly intracellularly (Li and Shah, 2003). The neutrophil NADPH 
oxidase is composed of membrane-associated subunits: p22 $2^{\text {phox }}$, and NOX, and four cytosolic regulatory subunits: $47^{\text {phox }}, \mathrm{p} 67^{\mathrm{phox}}$, $\mathrm{p} 40^{\text {phox }}$, and the small GTPase racl or rac2. NOX is the key catalytic subunit of the NADPH oxidase and in non-phagocytic cells possess several isoforms. Beside the phagocyte NADPH oxidase (NOX2; gp91 ${ }^{\text {phox }}$ ), the expression of six homologs (NOX1, NOX3, NOX4, NOX5, Duox1, and Duox2) has been identified (Afanas'ev, 2011). While the cytosolic regulatory components translocate to the membrane to form the active NADPH oxidase complex upon activation in the neutrophil (Babior et al., 2002), in the nonphagocytic cells preassembled functional enzyme complex is partly present intracellularly (Bayraktutan et al., 2000; Li and Shah, 2003). Although the non-phagocyte NADPH oxidase is constitutively active, its activity can be further up-regulated in response to vasoactive peptides (AngII, ET-1), hormones, growth factors, cytokines, and mechanical stress (Jaimes et al., 1998; Griendling et al., 2000; Li et al., 2002; Yasunari et al., 2002).

The NOX-dependent ROS signaling is an important factor responsible for development of many pathological processes in the ventricles during cardiac hypertrophy, remodeling, and heart failure (Murdoch et al., 2006). Recently, in an animal model of acute AF, increased expression of NOX2, NOX1, and enhanced expression of NOX4 were shown in the left ventricle after $6 \mathrm{~h}$ of atrial pacing (Goette et al., 2009; Bukowska et al., 2012). The AT1 receptor antagonist, irbesartan, and the multichannel inhibitor, dronedarone, efficiently prevented the up-regulation of NOX2 (Goette et al., 2009; Bukowska et al., 2012). The elevated expression of NOX2 and superoxide production in the left ventricle was also observed in a rabbit model of chronic heart failure (Yasunari et al., 2002). Several studies have shown a crucial role of NOX2 in the response to AngII-induced LV hypertrophy (Bendall et al., 2002; Li and Shah, 2003; Li et al., 2007). It was found that the regulatory compound $\mathrm{racl}$ initiated hypertrophic response (Hingtgen et al., 2006; Satoh et al., 2006). Amounts of the regulatory $\mathrm{p} 47^{\mathrm{phox}}$ (Hingtgen et al., 2006; Satoh et al., 2006) increase after myocardial infarction in the left ventricle and contribute to the NADPH oxidase dependent tissue remodeling (Doerries et al., 2007). NOX2 and NOX4 are the main isoforms expressed in the cardiac cells. NOX4, in contrast to NOX2, does not require the presence of regulatory oxidase proteins $\mathrm{p} 47^{\mathrm{phox}}$ or the GTPase rac. Moreover, NOX4 produces mainly hydrogen peroxide and only very small amounts of superoxide intracellularly (Serrander et al., 2007) and was found on internal membranes, in mitochondria (Ago et al., 2010; Kuroda et al., 2010), and also in perinuclear endoplasmic reticulum (Chen et al., 2008). The up-regulation in NOX4 expression was accompanied by mitochondrial dysfunction and apoptosis in the cardiomyocytes (Ago et al., 2010; Kuroda et al., 2010). NOX1 is an important isoform expressed particularly in vascular smooth muscle cells and is responsible for extracellular superoxide production in coronary arterial myocytes. Several studies have provided evidence that NOX1 oxidase is involved in mediating the hypertensive response to AngII in particular (Dikalova et al., 2005; Matsuno et al., 2005).

Recent data suggests, however, that induction of atrial NADPH oxidase activity or subunit expression is an early but transient mechanism in the natural course of AF development and progression (Reilly et al., 2011). With increasing duration of AF,
ROS production is shifted from NADPH oxidase to mitochondrial oxidases and uncoupled eNOS in the right atrium (Reilly et al., 2011). This is in full accordance with the observation that statins, which reduce ROS production by NADPH oxidases via inhibition of Racl, are effective in acute models of AF and in patients with post-operative AF, but fail to reduce ROS production in models of long-lasting AF or patients with permanent AF. Preoperative statin-treatment was shown to reduce myocardial $\mathrm{O}_{2}{ }^{-}$ and $\mathrm{ONOO}^{-}$production by reducing NADPH oxidase activity (Antoniades et al., 2012).

\section{VENTRICULAR MICROCIRCULATION DURING AF}

An induced episode of AF of up to $6 \mathrm{~h}$ has no effect on FFR (marker for epicardial flow) in pigs (Bukowska et al., 2012). In contrast, CFR (index of microvascular abnormalities if FFR is normal) is substantially reduced (about 50\%) after an AF episode of $6 \mathrm{~h}$. Interestingly, application of irbesartan and dronedarone could prevent microcirculatory flow abnormalities to occur whereas amiodarone has no effect on CRF (Figure 2). These results correspond to latest findings that dronedarone reduces the size and volume of induced cerebral and myocardial infarcts (Engelhorn et al., 2011; Skyschally and Heusch, 2011). Patients without previously documented coronary artery disease sometimes develop chest discomfort with the onset of AF (Fineschi et al., 2008). Furthermore, patients with AF have ventricular-flow abnormalities and a higher incidence of cardiac events (Abidov et al., 2004; Range et al., 2007). Consistent with this notion, coronary artery resistance is markedly elevated (by $62 \%$ ), whereas myocardial blood flow is substantially reduced in AF patients (Range et al., 2007). Vasodilatation in response to exercise is also compromised during AF (Berndt et al., 2007). The Doppler-derived coronary vascular resistance index has been reported to be increased by $67 \%$ in an experimental AF model (Range et al., 2007). Induction of AF for up to $6 \mathrm{~h}$ has no effect on FFR (marker of epicardial flow) in pigs (Bukowska et al., 2012); by contrast, CFR (index of microvascular abnormalities if FFR is normal) is substantially reduced (about 50\%) by short-term AF. Interestingly, irbesartan and dronedarone could prevent the occurrence of microcirculatory flow abnormalities whereas amiodarone had no effect (Figure 2). These results are in keeping with recent findings indicating that dronedarone reduces the size and volume of induced cerebral and myocardial infarcts (Engelhorn et al., 2011; Skyschally and Heusch, 2011).

\section{AF ALTERS VENTRICULAR EXPRESSION OF ISCHEMIA/HYPOXIA-RELATED GENE PANELS}

Atrial fibrillation provokes rapid and profound changes in the ventricular expression of ischemia/hypoxia-related genes (Bukowska et al., 2012). These expression changes were associated with and may result partially from microcirculatory abnormalities. Both the observed RAP-dependent limitation of flow reserve and the expression changes could be prevented by dronedarone. Interestingly, amiodarone does not reduce AF-induced flow abnormalities in the microvascular tree (Figure 2). The positive effect of dronedarone in brief episodes of AF is supported by the ATHENA trial, which found a reduced rate of acute coronary syndromes and reduced cardiovascular mortality in patients with AF (Hohnloser et al., 2009). 
A recent study could show that acute application of dronedarone during an induced myocardial infarction reduced the infarct size substantially (Figure 3). Nevertheless, in longlasting (6 month) AF, myocardial NADPH is not activated (Reilly et al., 2011), and thereby, positive effects through inhibition of NADPH are unrealistic to exist. Thus, the antioxidant effects of dronedarone should not be present in permanent AF. This is supported by the PALLAS trial, which showed negative outcome if patients with permanent AF are treated with dronedarone. In PALLAS, rates of stroke, myocardial infarction, and heart failure were almost doubled in dronedarone treated patients (Connolly et al., 2011). Thus, the therapeutic effect of dronedarone depends on the duration of AF, which is quite a unique finding.

Transcriptome analyses provided a first mechanistic insight into the pathophysiological processes mediating or even counteracting coronary and ventricular dysfunction during AF. Among the genes the expression of which was changed in response to RAP

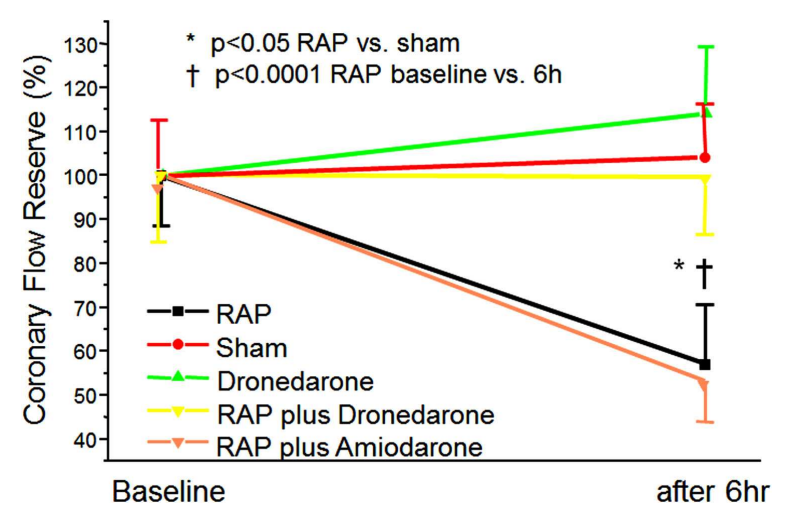

FIGURE 2 | Induction of ventricular-flow abnormalities in the ventricles during rapid atrial pacing (RAP) in comparison to unpaced controls using a porcine model. Effects of dronedarone and amiodarone demonstrated. Abbreviations are explained in the text adopted from Bukowska et al. (2012). were HIF-1, VEGFA, and PPARGC1 $\alpha$, all of them known to be induced in response to hypoxia or deprivation of nutrients (Arany et al., 2008). The regulation of VEGF expression in response to hypoxia is mediated by HIF-1 $\alpha$ (Ferrara et al., 2003). Under the same conditions, and independent of this canonical HIFpathway, increased PPARGC1 $\alpha$ exerts its strong angiogenic activity and induces VEGF expression by co-activating ERR- $\alpha$ (Arany et al., 2008). Thus, both HIF- $1 \alpha$ and PPARGC1 $\alpha$ appear to be critically involved in the angiogenic response to AF-dependent flow alterations and may provide protection against ischemic damage.

Rapid atrial pacing also led to an activation of the NF- $\kappa \mathrm{B}$ pathway in the left ventricle (Bukowska et al., 2012). ROS as intracellular messengers and redox effector molecules such as Trx and glutaredoxin (Grx) lead to the activation and nuclear translocation of this redox-sensitive transcription factor (Lillig and Holmgren, 2007). Consistent with the RAP-dependent ventricular activation of NF- $\kappa \mathrm{B}$, the expression of a panel of established down-stream targets of NF- $\kappa \mathrm{B}$ including VEGFA (Kiriakidis et al., 2003; Martin et al., 2009), Fn14, CCL2 (Lawrence et al., 2006), HIF1A (Kunsch and Medford, 1999; Bonello et al., 2007) as well as DnaJ family members, DNAJA4 and DNAJB9, that have been described as co-chaperones for the ATPase activity of Hsp70 and function to protect stressed cells from apoptosis (Qiu et al., 2006), was up-regulated in the left ventricle (Bukowska et al., 2012). Both DNAJA4 and DNAJB9, but also thioredoxin (Trx1; Bloom and Jaiswal, 2003) and peroxiredoxin I (PrxI; Ago et al., 2008) are antioxidant response element (AREs) regulated genes activated through nuclear factor-erythroid 2-related factor 2 (Nrf2) in response to oxidative stress. After phosphorylation by, e.g., PKC, $\mathrm{Nrf} 2$ translocates to the nucleus where it binds to AREs and transactivates target genes of, e.g., enzymes such as PrxI that regulate the intracellular amounts of ROS (Bloom and Jaiswal, 2003). It seems reasonable to assume that increased expression of anti-oxidative response genes, e.g., peroxiredoxins and DnaJ family members, is aimed at limiting stress-mediated tissue-damage. In this in vivo model of acute AF, dronedarone attenuated most of the ventricular changes in gene expression. In addition, RAP-dependent
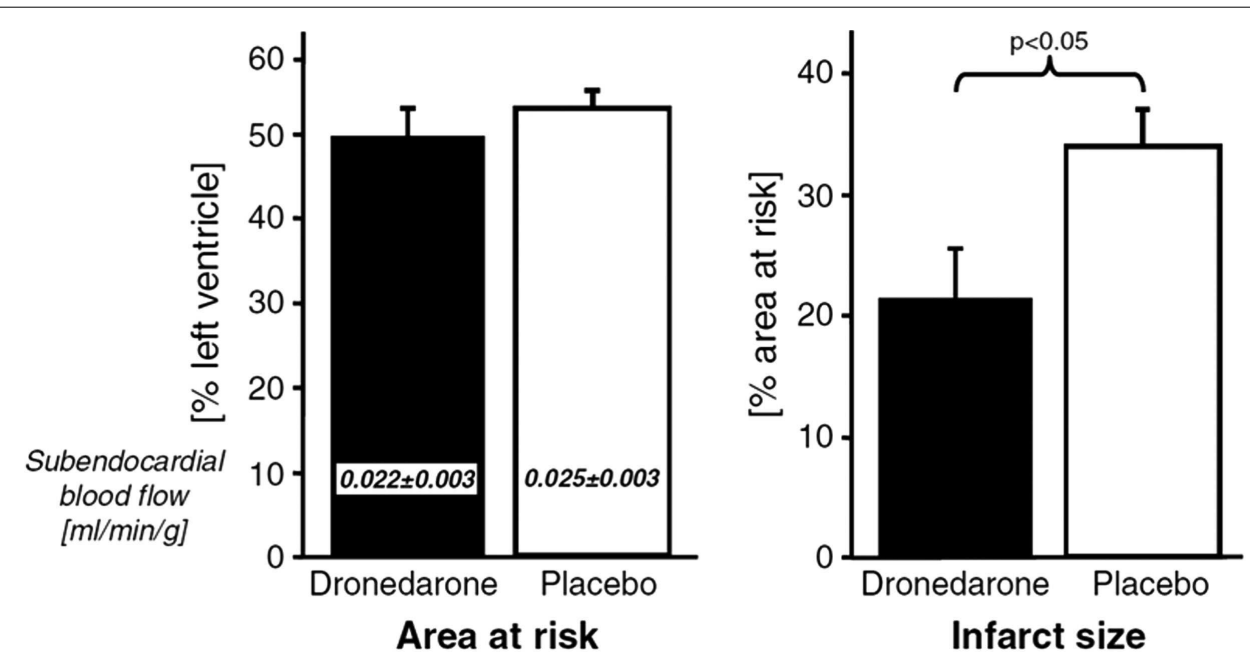

FIGURE 3 | Effect of dronedarone on size of acute myocardial infarctions adopted from Qiu et al. (2006). 
PKC phosphorylation, NADPH isoform expression, isoprostane release, and $\mathrm{I} \kappa \mathrm{B} \alpha$ phosphorylation were decreased. This, together with the attenuation of negative flow alterations may indicate that dronedarone beneficially affects very early steps of RAP-associated ventricular pathology, very likely by preventing ischemia/hypoxia itself.

PPARGC1, the multi-functional co-activator, is also involved in the regulation of cardiac mitochondrial functional capacity and cellular energy metabolism. In accordance with the observed increase in PPARGC1 and HIF-1 $\alpha$ expression, RAP provoked profound changes in the ventricular expression of important metabolic genes including hexokinase 2 (HK2), glycogen synthase kinase $3 \beta$ (GSK-3 $\beta$ ), muscle isoform of glycogen phosphorylase (PYGM), and acyl-coenzyme A dehydrogenase (ACADL; Bukowska et al., 2012). Interestingly, these metabolic changes were not affected by dronedarone, which suggests that other factors than deprivation of oxygen and nutrients contribute to the overall change of ventricular gene expression during AF.

It is fully established that even mild ischemia is associated with compromised mitochondrial function and requires metabolic adaption to maintain adequate ATP generation and cardiac output (Shohet and Garcia, 2007). Again, the activation of redoxsensitive transcription factors, namely HIF- $1 \alpha$ and PPARGC1, is responsible for these protective changes in the metabolism that

\section{REFERENCES}

Abidov, A., Hachamovitch, R., Rozanski, A., Hayes, S. W., Santos, M. M., Sciammarella, M. G., Cohen, I., Gerlach, J., Friedman, J. D., Germano, G., and Berman, D. S. (2004). Prognostic implications of atrial fibrillation in patients undergoing myocardial perfusion single-photon emission computed tomography. J. Am. Coll. Cardiol. 44, 1062-1070.

ACTIVE I Investigators, Yusuf, S., Healey, J. S., Pogue, J., Chrolavicius, S., Flather, M., Hart, R. G., Hohnloser, S. H., Joyner, C. D., Pfeffer, M. A., and Connolly, S. J. (2011). Irbesartan in patients with atrial fibrillation. N. Engl. J. Med. 364, 928-938.

Afanas'ev, I. (2011). ROS and RNS signaling in heart disorders: could antioxidant treatment be successful? Oxid. Med. Cell. Longev. 2011, 293769. doi: 10.1155/2011/293769

Ago, T., Kuroda, J., Pain, J., Fu, C., Li, H., and Sadoshima, J. (2010). Upregulation of NOX4 by hypertrophic stimuli promotes apoptosis and mitochondrial dysfunction in cardiac myocytes. Circ. Res. 106, 1253-1264.

Ago, T., Liu, T., Zhai, P., Chen, W., Li, H., Molkentin, J. D., Vatner, S. F., and Sadoshima, J. (2008). A redoxdependent pathway for regulating class II HDACs and cardiac hypertrophy. Cell 133, 978-993.

Ahmad, A., Ahmad, S., Schneider, B. K., Allen, C. B., Chang, L. Y., and White,

generally mediate the shift from aerobic metabolism and fatty acid utilization to glucose utilization via pyruvate oxidation or even to glycolytic metabolism (Bolukoglu et al., 1996; Seagroves et al., 2001). HIF-1, together with c-myc, mediates the induction of HK2 which contributes to shift glucose away from mitochondrial utilization and has also anti-oxidative effects (Ahmad et al., 2002; Kim et al., 2006). On this background, the observed ventricular induction of glycolytic gene expression during AF completely fits to the increased expression levels of HIF- $1 \alpha$ and PPARGC1 and, most importantly, demonstrate that the compromised microcirculatory flow leads to ischemia-like conditions. The latter activate multiple signaling pathways that are aimed at the improvement of oxygen supply, angiogenesis, cell survival, and adaption of metabolism (Figure 1).

\section{CONCLUSION}

AT induces oxidative stress in the atrial and ventricular myocardium. In the ventricles, AF causes alterations in gene expression and activation of specific signal transduction pathways. As a consequence, microcirculation is impaired, troponin can be released, which is associated with causing clinical symptoms like angina pectoris and dyspnea. It remains to be determined if these alterations are also related to the increased rate of death in $\mathrm{AF}$ patients shown by several epidemiologic studies.

NADPH oxidase. Arch. Biochem. Biophys. 397, 342-324.

Bayraktutan, U., Blayney, L., and Shah, A. M. (2000). Molecular characterization and localization of the $\mathrm{NAD}(\mathrm{P}) \mathrm{H}$ oxidase components gp91-phox and p22-phox in endothelial cells. Arterioscler. Thromb. Vasc. Biol. 20, 1903-1911.

Bendall, J. K., Cave, A. C., Heymes, C., Gall, N., and Shah, A. M. (2002). Pivotal role of a gp91(phox)-containing NADPH oxidase in angiotensin IIinduced cardiac hypertrophy in mice. Circulation 105, 293-296.

Berndt, C., Lillig, C. H., and Holmgren, A. (2007). Thiol-based mechanisms of the thioredoxin and glutaredoxin systems: implications for diseases in the cardiovascular system. Am. J. Physiol. Heart Circ. Physiol. 292, H1227-H1236.

Besse, S., Tanguy, S., Riou, B., Boucher, F., Bulteau, A. L., Le Page, C., Swynghedauw, B., and de Leiris, J. (2001). Coronary and aortic vasoreactivity protection with endothelin receptor antagonist, bosentan, after ischemia and hypoxia in aged rats. Eur. J. Pharmacol. 432, 167-175.

Bloom, D. A., and Jaiswal, A. K. (2003). Phosphorylation of Nrf2 at Ser40 by protein kinase $\mathrm{C}$ in response to antioxidants leads to the release of $\mathrm{Nrf} 2$ from INrf2, but is not required for Nrf2 stabilization/accumulation in the nucleus and transcriptional activation of antioxidant response element-mediated $\mathrm{NAD}(\mathrm{P}) \mathrm{H}$ : quinone oxidoreductase-1 gene expression. J. Biol. Chem. 278, 44675-44682.

Bolukoglu, H., Goodwin, G. W., Guthrie, P. H., Carmical, S. G., Chen, T. M., and Taegtmeyer, H. (1996). Metabolic fate of glucose in reversible low-flow ischemia of the isolated working rat heart. Am. J. Physiol. 270(Pt 2), H817-H826.

Bonello, S., Zahringer, C., BelAiba, R. S., Djordjevic, T., Hess, J., Michiels, C., Kietzmann, T., and Görlach, A. (2007). Reactive oxygen species activate the HIF-lalpha promoter via a functional NFkappaB site. Arterioscler. Thromb. Vasc. Biol. 27, 755-761.

Brown, A. M., Sease, K. L., Robey, J. L., Shofer, F. S., and Hollander, J. E. (2007). The risk for acute coronary syndrome associated with atrial fibrillation among ED patients with chest pain syndromes. Am. J. Emerg. Med. 25, 523-528.

Bruneau, B. G., Piazza, L. A., and de Bold, A. J. (1997). BNP gene expression is specifically modulated by stretch and ET-1 in a new model of isolated rat atria. Am. J. Physiol. 273(Pt 2), H2678-H2686.

Brunner, F., Leonhard, B., Kukovetz, W. R., and Mayer, B. (1997). Role of endothelin, nitric oxide and L-arginine release in ischaemia/reperfusion injury of rat heart. Cardiovasc. Res. 36, 60-66. 
Bukowska, A., Hammwöhner, M., Sixdorf, A., Schild, L., Wiswedel, I., Röhl, F. W., Wolke, C., Lendeckel, U., Aderkast, C., Bochmann, S., Chilukoti, R. K., Mostertz, J., Bramlage, P., and Goette, A. (2012). Dronedarone prevents microcirculatory abnormalities in the left ventricle during atrial tachypacing. $\mathrm{Br}$. J. Pharmacol. 166, 964-980.

Bukowska, A., Schild, L., Keilhoff, G., Hirte, D., Neumann, M., Gardemann, A., Neumann, K. H., Röhl, F. W., Huth, C., Goette, A., and Lendeckel, U. (2008). Mitochondrial dysfunction and redox signaling in atrial tachyarrhythmia. Exp. Biol. Med. (Maywood) 233, 558-574.

Cadenas, E., Wefers, H., Müller, A., Brigelius, R., and Sies, H. (1982). Active oxygen metabolites and their action in the hepatocyte. Studies on chemiluminescence responses and alkane production. Agents Actions Suppl. 11, 203-216.

Camici, P. G., and Crea, F. (2007). Coronary microvascular dysfunction. $N$. Engl. J. Med. 356, 830-840.

Cardin, S., Li, D., Thorin-Trescases, N., Leung, T. K., Thorin, E., and Nattel, S. (2003). Evolution of the atrial fibrillation substrate in experimental congestive heart failure: angiotensin-dependent and independent pathways. Cardiovasc. Res. 60, 315-325.

Carnes, C. A., Chung, M. K., Nakayama, T., Nakayama, H., Baliga, R. S., Piao, S., Kanderian, A., Pavia, S., Hamlin, R. L., McCarthy, P. M., Bauer, J. A., and Van Wagoner, D. R. (2001). Ascorbate attenuates atrial pacing-induced peroxynitrite formation and electrical remodeling and decreases the incidence of postoperative atrial fibrillation. Circ. Res. 89, E32-E38.

Chen, H., Li, D., Sawamura, T., Inoue, K., and Mehta, J. L. (2000). Upregulation of LOX-1 expression in aorta of hypercholesterolemic rabbits: modulation by losartan. Biochem. Biophys. Res. Commun. 276, 1100-1104.

Chen, K., Kirber, M. T., Xiao, H., Yang, Y., and Keaney, J. F. Jr. (2008). Regulation of ROS signal transduction by NADPH oxidase 4 localization. J. Cell Biol. 181, 1129-1139.

Connolly, S. J., Camm, A. J., Halperin, J. L., Joyner, C., Alings, M., Amerena, J., Atar, D., Avezum, Á., Blomström, P., Borggrefe, M., Budaj, A., Chen, S. A., Ching, C. K., Commerford, P., Dans, A., Davy, J. M., Delacrétaz, E., Di Pasquale, G., Diaz, R., Dorian, P., Flaker, G., Golitsyn, S., GonzalezHermosillo, A., Granger, C. B., Heidbüchel, H., Kautzner, J., Kim, J. S.,
Lanas, F., Lewis, B. S., Merino, J. L., Morillo, C., Murin, J., Narasimhan, C., Paolasso, E., Parkhomenko, A., Peters, N. S., Sim, K. H., Stiles, M. K., Tanomsup, S., Toivonen, L., Tomcsányi, J., Torp-Pedersen, C., Tse, H. F., Vardas, P., Vinereanu, D., Xavier, D., Zhu, J., Zhu, J. R., Baret-Cormel, L., Weinling, E., Staiger, C., Yusuf, S., Chrolavicius, S., Afzal, R., Hohnloser, S. H., and PALLAS Investigators. (2011). Dronedarone in highrisk permanent atrial fibrillation. $N$. Engl. J. Med. 365, 2268-2276.

Dammanahalli, K. J., and Sun, Z. (2008). Endothelins and NADPH oxidases in the cardiovascular system. Clin. Exp. Pharmacol. Physiol. 35, 2-6.

De Boer, R. A., Pinto, Y. M., and Van Veldhuisen, D. J. (2003). The imbalance between oxygen demand and supply as a potential mechanism in the pathophysiology of heart failure: the role of microvascular growth and abnormalities. Microcirculation 10, 113-126.

Dikalova, A., Clempus, R., Lassègue, B., Cheng, G., McCoy, J., Dikalov, S., San Martin, A., Lyle, A., Weber, D. S., Weiss, D., Taylor, W. R., Schmidt, H. H., Owens, G. K., Lambeth, J. D., and Griendling, K. K. (2005). NOX1 overexpression potentiates angiotensin II-induced hypertension and vascular smooth muscle hypertrophy in transgenic mice. Circulation 112, 2668-2676.

Doerries, C., Grote, K., Hilfiker-Kleiner, D., Luchtefeld, M., Schaefer, A., Holland, S. M., Sorrentino, S., Manes, C., Schieffer, B., Drexler, H., and Landmesser, U. (2007). Critical role of the $\mathrm{NAD}(\mathrm{P}) \mathrm{H}$ oxidase subunit $\mathrm{p} 47$ phox for left ventricular remodeling/dysfunction and survival after myocardial infarction. Circ. Res. 100, 894-903.

Doughan, A. K., Harrison, D. G., and Dikalov, S. I. (2008). Molecular mechanisms of angiotensin II mediated mitochondrial dysfunction. Linking mitochondrial oxidative damage and vascular endothelial dysfunction. Circ. Res. 102, 488-496.

Engelhorn, T., Schwarz, M. A., Heusch, G., Doerfler, A., and Schulz, R. (2011). Reduction of cerebral infarct size by dronedarone. Cardiovasc. Drugs Ther. 25, 523-529.

Ferrara, N., Frantz, G., LeCouter, J., Dillard-Telm, L., Pham, T., Draksharapu, A., Giordano, T., and Peale, F. (2003). Differential expression of the angiogenic factor genes vascular endothelial growth factor (VEGF) and endocrine glandderived VEGF in normal and polycystic human ovaries. Am. J. Pathol. 162, 1881-1893.

Fineschi, M., Bravi, A., and Gori, T. (2008). The "slow coronary flow" phenomenon: evidence of preserved coronary flow reserve despite increased resting microvascular resistances. Int. J. Cardiol. 127, 358-361.

Fontayne, A., Dang, P. M., GougerotPocidalo, M. A., and El-Benna, J. (2002). Phosphorylation of p47phox sites by PKC alpha, beta II, delta, and zeta: effect on binding to p22phox and on NADPH oxidase activation. Biochemistry 41, 7743-7750.

Fuster, V., Ryden, L. E., Cannom, D. S., Crijns, H. J., Curtis, A. B., Ellenbogen, K. A., Halperin, J. L., Le Heuzey, J. Y., Kay, G. N., Lowe, J. E., Olsson, S. B., Prystowsky, E. N., Tamargo, J. L., Wann, S., Smith, S. C. Jr., Jacobs, A. K., Adams, C. D., Anderson, J. L., Antman, E. M., Halperin, J. L., Hunt, S. A., Nishimura, R., Ornato, J. P., Page, R. L., Riegel, B., Priori, S. G., Blanc, J. J., Budaj, A., Camm, A. J., Dean, V., Deckers, J. W., Despres, C., Dickstein, K., Lekakis, J., McGregor, K., Metra, M., Morais, J., Osterspey, A., Tamargo, J. L., and Zamorano, J. L. (2006). ACC/AHA/ESC 2006 Guidelines for the Management of Patients with Atrial Fibrillation: a report of the American College of Cardiology/American Heart Association Task Force on Practice Guidelines and the European Society of Cardiology Committee for Practice Guidelines (Writing Committee to Revise the 2001 Guidelines for the Management of Patients With Atrial Fibrillation): developed in collaboration with the European Heart Rhythm Association and the Heart Rhythm Society. Circulation 114, e257-e354.

Galatius-Jensen, S., Wroblewski, H., Emmeluth, C., Bie, P., Haunsø, S., and Kastrup, J. (1996). Plasma endothelin in congestive heart failure: effect of the ACE inhibitor, fosinopril. Cardiovasc. Res. 32, 1148-1154.

Ghezzi, P., Bonetto, V., and Fratelli, M. (2005). Thiol-disulfide balance: from the concept of oxidative stress to that of redox regulation. Antioxid. Redox Signal. 7, 964-972.

Goette, A., Bukowska, A., Dobrev, D., Pfeiffenberger, J., Morawietz, H., Strugla, D., Wiswedel, I., Röhl, F.-W., Wolke, C., Bergmann, S., Bramlage, P., Ravens, U., and Lendeckel, U. (2009). Acute atrial tachyarrhythmia induces angiotensin II type 1 receptor-mediated oxidative stress and microvascular flow abnormalities in the ventricles. Eur. Heart J. 30, 1411-1420.

Goette, A., Bukowska, A., Lendeckel, U., Erxleben, M., Hammwohner, M., Strugala, D., Pfeiffenberger, J., Rohl, F. W., Huth, C., Ebert, M. P., Klein, H. U., and Rocken, C. (2008). Angiotensin II receptor blockade reduces tachycardia-induced atrial adhesion molecule expression. Circulation 117, 732-742.

Goette, A., Staack, T., Rocken, C., Arndt, M., Geller, J. C., Huth, C., Ansorge, S., Klein, H. U., and Lendeckel, U. (2000). Increased expression of extracellular signal-regulated kinase and angiotensin-converting enzyme in human atria during atrial fibrillation. J. Am. Coll. Cardiol. 35, 1669-1677.

Griendling, K. K., Sorescu, D., and Ushio-Fukai, M. (2000). NAD(P)H oxidase: role in cardiovascular biology and disease. Circ. Res. 86, 494-501.

Hasdai, D., Kornowski, R., and Battler, A. (1994). Endothelin and myocardial ischemia. Cardiovasc. Drugs Ther. 8, 589-599.

Heusch, G. (2008). Heart rate in the pathophysiology of coronary blood flow and myocardial ischaemia: benefit from selective bradycardic agents. Br. J. Pharmacol. 153, 1589-1601.

Heusch, G., Baumgart, D., Camici, P., Chilian, W., Gregorini, L., Hess, O., Indolfi, C., and Rimoldi, O. (2000). Alpha-adrenergic coronary vasoconstriction and myocardial ischemia in humans. Circulation 101, 689-694.

Hiller, K. H., Roder, F., Adami, P., Voll, S., Kowallik, P., Haase, A., Ertl, G., and Bauer, W. R (1997). Study of microcirculation by coloured microspheres and NMRmicroscopy in isolated rat heart: effect of ischaemia, endothelin-1 and endothelin-1 antagonist BQ 610. J. Mol. Cell. Cardiol. 29, 3115-3122.

Hingtgen, S. D., Tian, X., Yang, J., Dunlay, S. M., Peek, A. S., Wu, Y., Sharma R. V., Engelhardt, J. F., and Davisson, R. L. (2006). Nox2-containing NADPH oxidase and Akt activation play a key role in angiotensin II-induced cardiomyocyte hypertrophy. Physiol. Genomics 26, 180-191.

Hohnloser, S. H., Crijns, H. J., van Eickels, M., Gaudin, C., Page, R. L., Torp-Pedersen, C., Connolly, S. J., and ATHENA Investigators. (2009). Effect of dronedarone on cardiovascular events in atrial fibrillation. $N$. Engl. J. Med. 360, 668-678. 
Jaimes, E. A., Galceran, J. M., and Raij, L. (1998). Angiotensin II induces superoxide anion production by mesangial cells. Kidney Int. 54, 775-784.

Jones, D. P. (2006). Redefining oxidative stress. Antioxid. Redox Signal. 8, 1865-1879.

Jones, D. P. (2008). Radical-free biology of oxidative stress. Am. J. Physiol. Cell Physiol. 295, C849-C868.

Kern, M. J., Lerman, A., Bech, J. W., De Bruyne, B., Eeckhout, E., Fearon, W. F., Higano, S. T., Lim, M. J., Meuwissen, M., Piek, J. J., Pijls, N. H., Siebes, M., and Spaan, J. A. (2006). Physiological assessment of coronary artery disease in the cardiac catheterization laboratory: a scientific statement from the American Heart Association Committee on Diagnostic and Interventional Cardiac Catheterization, Council on Clinical Cardiology. Circulation 114, 1321-1341.

Kim, J. W., Tchernyshyov, I., Semenza, G. L., and Dang, C. V. (2006). HIF1-mediated expression of pyruvate dehydrogenase kinase: a metabolic switch required for cellular adaptation to hypoxia. Cell Metab. 3, 177-185.

Kim, Y. M., Kattach, H., Ratnatunga, C., Pillai, R., Channon, K. M., and Casadei, B. (2008). Association of atrial nicotinamide adenine dinucleotide phosphate oxidase activity with the development of atrial fibrillation after cardiac surgery. J. Am. Coll. Cardiol. 51, 68-74.

Kinoshita, O., Yoshimi, H., Nagata, S., Ishikura, F., Kimura, K., Yamabe, T., Takagaki, K., Miyatake, K., and Omae, T. (1993). Rapid increase in plasma endothelin concentrations during percutaneous balloon dilatation of the mitral valve in patients with mitral stenosis. Br. Heart J. 69 , 322-326.

Kiriakidis, S., Andreakos, E., Monaco, C., Foxwell, B., Feldmann, M., and Paleolog, E. (2003). VEGF expression in human macrophages is NFkappaB-dependent: studies using adenoviruses expressing the endogenous NF-kappaB inhibitor IkappaBalpha and a kinase-defective form of the IkappaB kinase 2. J. Cell. Sci. $116,665-674$.

Kochiadakis, G. E., Skalidis, E. I., Kalebubas, M. D., Igoumenidis, N. E., Chrysostomakis, S. I., Kanoupakis, E. M., Simantirakis, E. N., and Vardas, P. E. (2002). Effect of acute atrial fibrillation on phasic coronary blood flow pattern and flow reserve in humans. Eur. HeartJ. 23, 734-741.

Korantzopoulos, P., Kolettis, T. M., Kountouris, E., Dimitroula, V.,
Karanikis, P., Pappa, E., Siogas, K., and Goudevenos, J. A. (2005). Oral vitamin $\mathrm{C}$ administration reduces early recurrence rates after electrical cardioversion of persistent atrial fibrillation and attenuates associated inflammation. Int. J. Cardiol. 102, 321-326.

Kunsch, C., and Medford, R. M. (1999). Oxidative stress as a regulator of gene expression in the vasculature. Circ. Res. 85, 753-766.

Kuroda, J., Ago, T., Matsushima, S., Zhai, P., Schneider, M. D., and Sadoshima, J. (2010). NADPH oxidase 4 (NOX4) is a major source of oxidative stress in the failing heart. Proc. Natl. Acad. Sci. U.S.A. 107, 15565-15570.

Lawrence, D. M., Seth, P., Durham, L., Diaz, F., Boursiquot, R., Ransohoff, R. M., and Major, E. O. (2006). Astrocyte differentiation selectively upregulates CCL2/monocyte chemoattractant protein-1 in cultured human brain-derived progenitor cells. Glia 53, 81-91.

Li, J. M., Gall, N. P., Grieve, D. J., Chen, M., and Shah, A. M. (2002). Activation of NADPH oxidase during progression of cardiac hypertrophy to failure. Hypertension 40, 477-484.

Li, J. M., and Shah, A. M. (2003). ROS generation by nonphagocytic NADPH oxidase: potential relevance in diabetic nephropathy. J. Am. Soc. Nephrol. 14(Suppl. 3), S221-S226.

Li, X., Zima, A. V., Sheikh, F., Blatter, L. A., and Chen, J. (2005). Endothelin-1-induced arrhythmogenic $\mathrm{Ca}^{2+}$ signaling is abolished in atrial myocytes of inositol-1,4,5trisphosphate(IP3)-receptor type 2-deficient mice. Circ. Res. 96, 1274-1281.

Li, Y. L., Gao, L., Zucker, I. H., and Schultz, H. D. (2007). NADPH oxidase-derived superoxide anion mediates angiotensin II-enhanced carotid body chemoreceptor sensitivity in heart failure rabbits. Cardiovasc. Res. 75, 546-554.

Lillig, C. H., and Holmgren, A. (2007). Thioredoxin and related molecules from biology to health and disease. Antioxid. Redox Signal. 9, 25-47.

Lin, Y. K., Lai, M. S., Chen, Y. C., Cheng, C. C., Huang, J. H., Chen, S. A., Chen, Y. J., and Lin, C. I. (2012). Hypoxia and reoxygenation modulate the arrhythmogenic activity of the pulmonary vein and atrium. Clin. Sci. 122, 121-132.

Love, M. P., Ferro, C. J., Haynes, W. G., Plumpton, C., Davenport, A. P., Webb, D. J., and McMurray, J. J. (2000). Endothelin receptor antagonism in patients with chronic heart failure. Cardiovasc. Res. 47, 166-172.
Martin, D., Galisteo, R., and Gutkind, J. S. (2009). CXCL8/IL8 stimulates vascular endothelial growth factor (VEGF) expression and the autocrine activation of VEGFR2 in endothelial cells by activating NFkappaB through the CBM (Carma3/Bcl10/Malt1) complex. $J$. Biol. Chem. 284, 6038-6042.

Matsuno, K., Yamada, H., Iwata, K. Jin, D., Katsuyama, M., Matsuki, M., Takai, S., Yamanishi, K., Miyazaki, M., Matsubara, H., and YabeNishimura, C. (2005). NOX1 is involved in angiotensin II-mediated hypertension: a study in NOX1deficient mice. Circulation 112, 2677-2685.

Matsuzawa, A., and Ichijo, H. (2008). Redox control of cell fate by MAP kinase: physiological roles of ASK1MAP kinase pathway in stress signaling. Biochim. Biophys. Acta 1780 1325-1336.

Mayyas, F., Niebauer, M., Zurick, A., Barnard, J., Gillinov, A. M., Chung, M. K., and Van Wagoner, D. R. (2010). Association of left atrial endothelin-1 with atrial rhythm, size, and fibrosis in patients with structural heart disease. Circ. Arrhythm. Electrophysiol. 3, 369-379.

Mollnau, H., Wendt, M., Szöcs, K., Lassègue, B., Schulz, E., Oelze, M. Li, H., Bodenschatz, M., August, M., Kleschyov, A. L., Tsilimingas, N. Walter, U., Förstermann, U., Meinertz, T., Griendling, K., and Münzel, T. (2002). Effects of angiotensin II infusion on the expression and function of $\mathrm{NAD}(\mathrm{P}) \mathrm{H}$ oxidase and components of nitric oxide/cGMP signaling. Circ. Res. 90, E58-E65.

Murdoch, C. E., Zhang, M., Cave, A. C., and Shah, A. M. (2006). NADPH oxidase-dependent redox signalling in cardiac hypertrophy, remodelling and failure. Cardiovasc. Res. 71 208-215.

Nagase, T., Fukuchi, Y., Jo, C., Teramoto, S., Uejima, Y., Ishida, K. Shimizu, T., and Orimo, H. (1990). Endothelin-1 stimulates arachidonate 15 -lipoxygenase activity and oxygen radical formation in the rat distal lung. Biochem. Biophys. Res. Commun. 168, 485-489.

Neubauer, S., Zimmermann, S., Hirsch, A., Pulzer, F., Tian, R., Bauer, W., Bauer, B., and Ertl, G. (1991). Effects of endothelin-1 in the isolated heart in ischemia/reperfusion and hypoxia/reoxygenation injury. $J$. Mol. Cell. Cardiol. 23, 1397-1409.

Nishida, K., Qi, X. Y., Wakili, R., Comtois, P., Chartier, D., Harada, M., Iwasaki, Y. K., Romeo, P., Maguy, A., Dobrev, D., Michael, G., Talajic, M., and Nattel, S. (2011). Mechanisms of atrial tachyarrhythmias associated with coronary artery occlusion in a chronic canine model. Circulation 123, 137-146

Oudot, A., Vergely, C., EcarnotLaubriet, A., and Rochette, L. (2003). Angiotensin II activates $\mathrm{NADPH}$ oxidase in isolated rat hearts subjected to ischaemiareperfusion. Eur. J. Pharmacol. 462, 145-154.

Qiu, X. B., Shao, Y. M., Miao, S., and Wang, L. (2006). The diversity of the DnaJ/Hsp40 family, the crucial partners for Hsp70 chaperones. Cell. Mol. Life Sci. 63, 2560-2570.

Range, F. T., Schafers, M., Acil, T., Schafers, K. P., Kies, P., Paul, M., Hermann, S., Brisse, B., Breithardt, G., Schober, O., and Wichter, T. (2007). Impaired myocardial perfusion and perfusion reserve associated with increased coronary resistance in persistent idiopathic atrial fibrillation. Eur. Heart J. 28, 2223-2230.

Reilly, S. N., Jayaram, R., Nahar, K., Antoniades, C., Verheule, S., Channon, K. M., Alp, N. J., Schotten, U., and Casadei, B. (2011). Atrial sources of reactive oxygen species vary with the duration and substrate of atrial fibrillation: implications for the antiarrhythmic effect of statins. Circulation 124, 1107-1117.

Rinckel, L. A., Faris, S. L., Hitt, N. D., and Kleinberg, M. E. (1999). Rac1 disrupts p67phox/p40phox binding: a novel role for Rac in NADPH oxidase activation. Biochem. Biophys. Res. Commun. 263, 118-122.

Rivard, L., Sinno, H., ShiroshitaTakeshita, A., Schram, G., Leung, T. K., and Nattel, S. (2007). The pharmacological response of ischemia-related atrial fibrillation in dogs: evidence for substratespecific efficacy. Cardiovasc. Res. 74, 104-113.

Rubens, C., Ewert, R., Halank, M., Wensel, R., Orzechowski, H. D., Schultheiss, H. P., and Hoeffken, G. (2001). Big endothelin-1 and endothelin-1 plasma levels are correlated with the severity of primary pulmonary hypertension. Chest 120 , 1562-1569.

Satoh, M., Ogita, H., Takeshita, K. Mukai, Y., Kwiatkowski, D. J., and Liao, J. K. (2006). Requirement of Racl in the development of cardiac hypertrophy. Proc. Natl. Acad. Sci. U.S.A. 103, 7432-7437.

Seagroves, T. N., Ryan, H. E., Lu, H., Wouters, B. G., Knapp, M., Thibault, P., Laderoute, K., and Johnson, R. S. (2001). Transcription factor HIF-1 is a necessary mediator of the Pasteur 
effect in mammalian cells. Mol. Cell. Biol. 21, 3436-3444.

Serrander, L., Cartier, L., Bedard, K., Banfi, B., Lardy, B., Plastre, O., Sienkiewicz, A., Fórró, L., Schlegel, W., and Krause, K. H. (2007). NOX4 activity is determined by mRNA levels and reveals a unique pattern of ROS generation. Biochem. J. 406, 105-114.

Shohet, R. V., and Garcia, J. A. (2007). Keeping the engine primed: HIF factors as key regulators of cardiac metabolism and angiogenesis during ischemia. J. Mol. Med. 85, 1309-1315.

Sinno, H., Derakhchan, K., Libersan, D., Merhi, Y., Leung, T. K., and Nattel, S. (2003). Atrial ischemia promotes atrial fibrillation in dogs. Circulation 107, 1930-1936.

Skyschally, A., and Heusch, G. (2011). Reduction of myocardial infarct size by dronedarone in pigs a pleiotropic action? Cardiovasc. Drugs Ther. 25, 197-201.

Sugden, P. H. (2003). An overview of endothelin signaling in the cardiac myocyte. J. Mol. Cell. Cardiol. 35, 871-886.
Takahashi, N., Ishibashi, Y., Shimada, T., Sakane, T., Ohata, S., Sugamori, T., Ohta, Y., Inoue, S., Nakamura, K., Shimizu, H., Katoh, H., and Murakami, Y. (2002). Impaired exercise-induced vasodilatation in chronic atrial fibrillation - role of endotheliumderived nitric oxide. Circ. J. 66, 583-538.

Van Gelder, I. C., Hagens, V. E., Bosker, H. A., Kingma, J. H., Kamp, O., Kingma, T., Said, S. A., Darmanata, J. I., Timmermans, A. J., Tijssen, J. G., and Crijns, H. J. (2002). A comparison of rate control and rhythm control in patients with recurrent persistent atrial fibrillation. N. Engl. J. Med. 347, 1834-1840.

White, M., Rouleau, J. L., Hall, C., Arnold, M., Harel, F., Sirois, P., Greaves, S., Solomon, S., Ajani, U., Glynn, R., Hennekens, C., and Pfeffer, M. (2001). Changes in vasoconstrictive hormones, natriuretic peptides, and left ventricular remodeling soon after anterior myocardial infarction. Am. Heart J. 142, 1056-1064.
Wyse, D. G., Waldo, A. L., DiMarco, J. P., Domanski, M. J., Rosenberg, Y., Schron, E. B., Kellen, J. C., Greene, H. L., Mickel, M. C., Dalquist, J. E., and Corley, S. D. (2002). A comparison of rate control and rhythm control in patients with atrial fibrillation. N. Engl. J. Med. 347, 1825-1833.

Yasunari, K., Maeda, K., Nakamura, M., and Yoshikawa, J. (2002). Pressure promotes angiotensin II - mediated migration of human coronary smooth muscle cells through increase in oxidative stress. Hypertension 39(2 Pt 2), 433-437.

Zhang, Y., Griendling, K. K., Dikalova, A., Owens, G. K., and Taylor, W. R. (2005). Vascular hypertrophy in angiotensin II-induced hypertension is mediated by vascular smooth muscle cell-derived $\mathrm{H} 2 \mathrm{O} 2$. Hypertension 46, 732-737.

Zolk, O., Quattek, J., Sitzler, G. Schrader, T., Nickenig, G., Schnabel, P., Shimada, K., Takahashi, M., and Böhm, M. (1999). Expression of endothelin-1, endothelin-converting enzyme, and endothelin receptors in chronic heart failure. Circulation 99, 2118-2123

Conflict of Interest Statement: The authors declare that the research was conducted in the absence of any commercial or financial relationships that could be construed as a potential conflict of interest.

Received: 22 January 2012; accepted: 11 June 2012; published online: 05 July 2012. Citation: Goette A, Bukowska A, Lillig $\mathrm{CH}$ and Lendeckel $U$ (2012) Oxidative stress and microcirculatory flow abnormalities in the ventricles during atrial fibrillation. Front. Physio. 3:236. doi: 10.3389/fphys.2012.00236

This article was submitted to Frontiers in Cardiac Electrophysiology, a specialty of Frontiers in Physiology.

Copyright (c) 2012 Goette, Bukowska, Lillig and Lendeckel. This is an openaccess article distributed under the terms of the Creative Commons Attribution License, which permits use, distribution and reproduction in other forums, provided the original authors and source are credited and subject to any copyright notices concerning any third-party graphics etc. 